\title{
Adsorption Behavior of Lithium from Seawater using Manganese Oxide Adsorbent ${ }^{*}$
}

\author{
Takaaki WAJIMA, Kenzo MUNAKATA and Tatsuhiko UDA ${ }^{1)}$ \\ Graduate School of Engineering and Resource Science, Akita University, 1-1 Tegata-gakuen-cho, Akita 010-8502, Japan \\ ${ }^{1)}$ National Institute of Fusion Science, 322-6 Oroshi-cho, Toki, Gifu 509-5292, Japan
}

(Received 22 November 2011 / Accepted 13 February 2012)

\begin{abstract}
The deuterium-tritium (D-T) fusion reactor system is expected to provide the main source of electricity in the future. Large amounts of lithium will be required, dependent on the reactor design concept, and alternative resources should be found to provide lithium inventories for nuclear fusion plants. Seawater has recently become an attractive source of this element and the separation and recovery of lithium from seawater by co-precipitation, solvent extraction and adsorption have been investigated. Amongst these techniques, the adsorption method is suitable for recovery of lithium from seawater, because certain inorganic ion-exchange materials, especially spinel-type manganese oxides, show extremely high selectivity for the lithium ion. In this study, we prepared a lithium adsorbent $\left(\mathrm{HMn}_{2} \mathrm{O}_{4}\right)$ by elution of spinel-type lithium di-manganese-tetra-oxide $\left(\mathrm{LiMn}_{2} \mathrm{O}_{4}\right)$ and examined the kinetics of the adsorbent for lithium ions in seawater using a pseudo-second-order kinetic model. The intermediate, $\mathrm{LiMn}_{2} \mathrm{O}_{4}$, can be synthesized from $\mathrm{LiOH} \cdot \mathrm{H}_{2} \mathrm{O}$ and $\mathrm{Mn}_{3} \mathrm{O}_{4}$, from which the lithium adsorbent can subsequently be prepared via acid treatment., The adsorption kinetics become faster and the amount of lithium adsorbed on the adsorbent increases with increasing solution temperature. The thermodynamic values, $\Delta G^{0}, \Delta H^{0}$ and $\Delta S^{0}$, indicate that adsorption is an endothermic and spontaneous process.
\end{abstract}

(c) 2012 The Japan Society of Plasma Science and Nuclear Fusion Research

Keywords: lithium recovery, seawater, adsorption, manganese dioxide, kinetics of lithium adsorption in seawater, pseudo-second-kinetic model

DOI: $10.1585 /$ pfr.7.2405021

\section{Introduction}

The deuterium-tritium (D-T) fusion reactor system is expected to provide the main source of electricity in the future, without serious releases of hazardous products such as the tritium radioisotope. Lithium will be required in amounts that depend on reactor design. When liquid lithium is used as a tritium breeder and a coolant, lithium inventories are large [1].

Lithium has recently been of great interest in many fields of science and technology. The demand for lithium has been increasing dramatically, because of its broad applicability as a raw material for large-capacity rechargeable batteries and light aircraft alloys for example. Lithium is now recovered from mines and salt lakes, which contain about 33 millions tons of lithium globally [2]. Although the amount of lithium available from those sources is currently sufficient, alternative resources should be found to satisfy lithium inventories for nuclear fusion plants and the increasing demand for batteries in the near future.

Seawater contains 230 billion tons of lithium in total [3] and has therefore recently become an attractive source of this element, and the separation and recovery of lithium from seawater, for example by co-precipitation, solvent ex-

author's e-mail: wajima@gipc.akita-u.ac.jp

*) This article is based on the presentation at the 21 st International Toki Conference (ITC21). traction and adsorption, have been investigated [4-7]. For both economic and environmental reasons, the adsorption method is the most promising for the recovery of lithium from seawater when a suitable adsorbent is available. Certain inorganic ion-exchange materials show extremely high selectivity for lithium ions, while organic ion-exchange resins seem to be unsuitable because of their low selectivity for the lithium ion [8-11]. Among these inorganic adsorbents, spinel-type manganese oxides are interesting materials because of their extremely high selective affinity toward lithium ions [12-17]. However, little information is available on the behavior of this adsorbent for adsorption of lithium from seawater.

In this study, we prepared a lithium adsorbent by elution of spinel-type lithium di-manganese-tetra-oxide $\left(\mathrm{LiMn}_{2} \mathrm{O}_{4}\right)$ using two preparation methods and the adsorption kinetics for lithium ions in seawater were examined.

\section{Experimental}

\subsection{Preparation of adsorbent}

Two mixtures were prepared as starting materials. One was a dry mixture of powdered $\mathrm{Mn}_{3} \mathrm{O}_{4}$ and $\mathrm{LiOH} \cdot \mathrm{H}_{2} \mathrm{O}$, and the other was a mixed slurry of powdered $\mathrm{Mn}_{3} \mathrm{O}_{4}$ and $\mathrm{LiOH}$ solution. The molar ratio of $\mathrm{Li} / \mathrm{Mn}$ in each preparation was 0.5 and each mixture was ground 
for $15 \mathrm{~min}$. The mixture was sintered at $425^{\circ} \mathrm{C}$ for $5 \mathrm{~h}$ in an electric oven, then cooled to room temperature. The sintered mixture was ground again for $15 \mathrm{~min}$ and then sintered at $500^{\circ} \mathrm{C}$ for $5 \mathrm{~h}$. After cooling to room temperature, a Li-type intermediate $\left(\mathrm{LiMn}_{2} \mathrm{O}_{4}\right)$ was obtained. The intermediate was treated with $1.0 \mathrm{~mol} / \mathrm{L} \mathrm{HCl}$ solution (overnight, five times), for ion exchange between $\mathrm{Li}^{+}$in the intermediate and $\mathrm{H}^{+}$in $\mathrm{HCl}$ solution to obtain $\mathrm{H}$-type product $\left(\mathrm{HMn}_{2} \mathrm{O}_{4}\right)$. The molar ratio of $\mathrm{H}^{+}$in $\mathrm{HCl}$ solution to $\mathrm{Li}^{+}$in the intermediate was greater than 40 . The Li-type intermediate and $\mathrm{H}$-type product obtained from powder mixture are identified hereafter as $\mathrm{LiMn}_{2} \mathrm{O}_{4}-1$ and $\mathrm{HMn}_{2} \mathrm{O}_{4}-1$, respectively, and those obtained from the slurry as $\mathrm{LiMn}_{2} \mathrm{O}_{4}-2$ and $\mathrm{HMn}_{2} \mathrm{O}_{4}-2$, respectively.

The composition of the Li-type intermediates and $\mathrm{H}$ type products were determined after dissolving the powder dissolving in a mixture of $30 \mathrm{wt} \% \mathrm{H}_{2} \mathrm{O}_{2}$ and $1 \mathrm{~mol} / \mathrm{L} \mathrm{HCl}$ by an inductively coupled plasma emission spectrophotometer (ICP-AES, Seiko Instruments, SPS3000). The characteristics of the crystal structure of the intermediates and products were measured using a powder X-ray diffractometer (XRD, Rigaku, Rint-2500).

\subsection{Lithium adsorption in seawater}

The H-type powder product $(0.1 \mathrm{~g})$ was added into modified seawater solution containing $1 \mathrm{mmol} / \mathrm{L} \mathrm{Li}$ ion (200 mL), prepared by adding $\mathrm{LiCl}$ into seawater obtained from Imari Bay, Saga Prefecture, Japan, and stirred with a magnetic stirrer at 5,25 and $60^{\circ} \mathrm{C}$. Aliquots $(2.5 \mathrm{~mL})$ of each sample were removed at varying time intervals during stirring to monitor the reaction over a period of $24 \mathrm{~h}$. The aliquots were filtered and the concentrations of $\mathrm{Li}^{+}$in the filtrate were analyzed by ICP-AES. The corresponding amounts adsorbed $\left(q_{\mathrm{Li}}[\mathrm{mmol} / \mathrm{g}]\right)$ and the recovery ratio $(R$ $[\%]$ ) were determined from the material balance, as follows.

$$
\begin{aligned}
& q_{\mathrm{Li}}=\frac{\left(C_{\mathrm{Li} 0}-C_{\mathrm{Li}}\right) \bullet V}{W} \\
& R=\frac{\left(C_{\mathrm{Li} 0}-C_{\mathrm{Li}}\right)}{C_{\mathrm{Li} 0}} \times 100
\end{aligned}
$$

where $C_{\mathrm{Li} 0}$ and $C_{\mathrm{Li}}$ are initial and analytical concentrations of $\mathrm{Li}^{+}$in the aqueous phase $[\mathrm{mmol} / \mathrm{L}], V$ is volume of aqueous solution [L], and $W$ is weight of adsorbent [g]. The $\mathrm{pH}$ of the aqueous phase was measured with a $\mathrm{pH}$ meter (Horiba F-23).

\section{Results and Discussion}

\subsection{Lithium adsorption in seawater}

Figure 1 shows XRD patterns of the raw materials, (a) $\mathrm{LiOH} \cdot \mathrm{H}_{2} \mathrm{O}$ and (b) $\mathrm{Mn}_{3} \mathrm{O}_{4}$, and the intermediates, (c) $\mathrm{LiMn}_{2} \mathrm{O}_{4}-1$ and (d) $\mathrm{LiMn}_{2} \mathrm{O}_{4}-2$. The intermediates show the peaks of the spinel structure, which differ from those of the raw materials. It is clearly shown that $\mathrm{LiMn}_{2} \mathrm{O}_{4}$ can be synthesized from $\mathrm{LiOH} \cdot \mathrm{H}_{2} \mathrm{O}$ and $\mathrm{Mn}_{3} \mathrm{O}_{4}$ by both preparation methods.

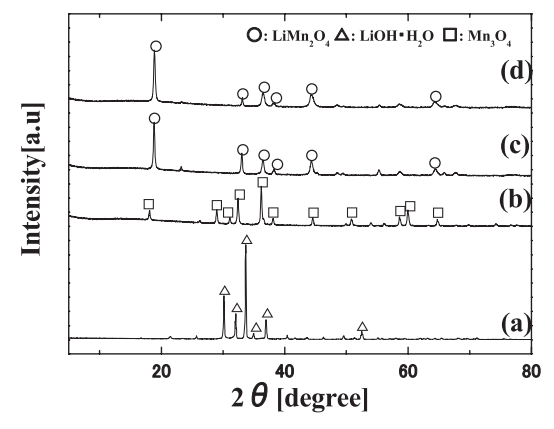

Fig. 1 XRD patterns of (a) $\mathrm{LiOH} \cdot \mathrm{H} 2 \mathrm{O}$, (b) $\mathrm{Mn}_{3} \mathrm{O}_{4}$, (c) $\mathrm{LiMn}_{2} \mathrm{O}_{4}-1$ and (d) $\mathrm{LiMn}_{2} \mathrm{O}_{4}-2$.
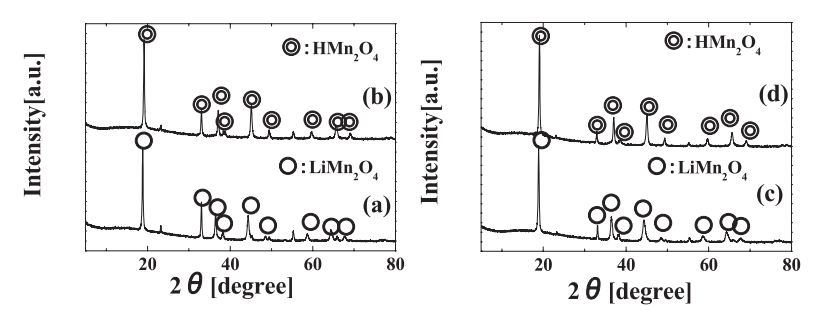

Fig. 2 XRD patterns of (a) $\mathrm{LiMn}_{2} \mathrm{O}_{4}-1$, (b) $\mathrm{HMn}_{2} \mathrm{O}_{4}-1$, (c) $\mathrm{LiMn}_{2} \mathrm{O}_{4}-2$ and (d) $\mathrm{HMn}_{2} \mathrm{O}_{4}-2$.

Figure 2 shows XRD patterns of the intermediates, (a) $\mathrm{LiMn}_{2} \mathrm{O}_{4}-1$ and (c) $\mathrm{LiMn}_{2} \mathrm{O}_{4}-2$, and the products obtained after $\mathrm{HCl}$ treatment, (b) $\mathrm{HMn}_{2} \mathrm{O}_{4}-1$ and (b) $\mathrm{HMn}_{2} \mathrm{O}_{4}-2$. Both products indicate the same peak patterns as the intermediate peaks. It is considered that the H-type product can be prepared by retaining the crystal structure of the intermediate after acid treatment, which means that $\mathrm{Li}^{+}$in the intermediate replace $\mathrm{H}^{+}$in the solution by ion exchange. It is noted that approximately $40 \%$ of $\mathrm{Li}^{+}$was eluted from both intermediates by the five acid treatments, meaning, to be precise, that both products were $\mathrm{H}_{0.4} \mathrm{Li}_{0.6} \mathrm{Mn}_{2} \mathrm{O}_{4}$.

From these results, we conclude that the $\mathrm{H}$-type product can be prepared by elution of spinel-type $\mathrm{LiMn}_{2} \mathrm{O}_{4}$ intermediates using two preparation methods.

\subsection{Lithium adsorption in seawater}

Figure 3 shows the adsorbed amounts adsorbed and recovery ratios of lithium ions from modified seawater on (a) $\mathrm{HMn}_{2} \mathrm{O}_{4}-1$ and (b) $\mathrm{HMn}_{2} \mathrm{O}_{4}-2$ products at temperatures ranging from 5 to $60^{\circ} \mathrm{C}$ as a function of reaction time. It is noted that the $\mathrm{pH}$ of the solution was held constant at $\mathrm{pH} 8.1$ during the reaction. These figures results indicate that both $\mathrm{HMn}_{2} \mathrm{O}_{4}$ products can adsorb lithium ions from seawater. With increasing reaction temperature, the amounts of lithium adsorbed were higher and the adsorption rates were faster. Lithium recoveries from modified seawater using both products reached approximately $100 \%$ at $60^{\circ} \mathrm{C}$. This means that $\mathrm{Li}$ adsorption at $60^{\circ} \mathrm{C}$ approached $1.5 \mathrm{mmol} / \mathrm{g}$ with no residual $\mathrm{Li}^{+}$ions in the solution. Thus, both products can effectively recover lithium ions from seawater. The $\mathrm{Li}$ adsorption capacity of $\mathrm{HMn}_{2} \mathrm{O}_{4}-2$ was 

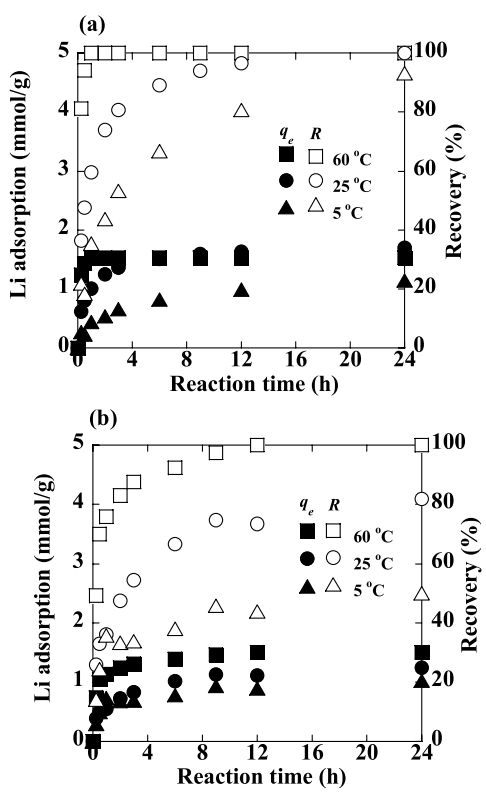

Fig. 3 Amounts adsorbed and recovery ratios of lithium from modified seawater on (a) $\mathrm{HMn}_{2} \mathrm{O}_{4}-1$ and (b) $\mathrm{HMn}_{2} \mathrm{O}_{4}-2$.

lower than that of $\mathrm{HMn}_{2} \mathrm{O}_{4}$-1. It is unclear why the adsorbent made by the slurry method was inferior to that made by the powder mixture method. One might speculate that the adsorbent made by the slurry method would have pores with the size of hydrated lithium ions $(240 \mathrm{pm})$, while the adsorbent made by the powder mixture method would have pores the size of lithium ions $(73 \mathrm{pm})$. Therefore, the adsorbent made by the slurry method has a larger pore size than not only $\mathrm{Li}^{+}(73 \mathrm{pm})$ but also $\mathrm{Na}^{+}(116 \mathrm{pm}), \mathrm{K}^{+}$ (152 pm), $\mathrm{Mg}^{2+}(86 \mathrm{pm})$, and $\mathrm{Ca}^{2+}$ (114 pm) [18]. Therefore, the adsorbent made by slurry method has lower selectivity for $\mathrm{Li}$ ions than that made by the powder method, and $\mathrm{Li}$ adsorption is decreased by competition from other cations in seawater.

The experimental kinetic data were fitted using a pseudo-second order kinetic model [19,20]:

$$
\frac{t}{q_{\mathrm{t}}}=\frac{1}{k \bullet q_{\mathrm{e}}^{2}}+\frac{1}{q_{\mathrm{e}} \bullet t}
$$

where $k(\mathrm{~g} /(\mathrm{mmol} \cdot \mathrm{h}))$ is the second order rate constant. Equations (3) was applied in the time interval between $t=$ 0 and $t=t_{\mathrm{e}}$ (i. e. the equilibration time, which was usually different for the various adsorption systems). $q_{\mathrm{e}}(\mathrm{mmol} / \mathrm{g})$ is the amount of lithium adsorbed at $t_{\mathrm{e}}$. The values of $k, q_{\mathrm{e}}$, and $R^{2}$ (i. e. the linear correlation coefficient) are set out in Table 1 . From the $R^{2}$ values, it follows that the experimental data fit well to pseudo-second- order model, confirming that the adsorption process is second-order.

From the results for $q_{\mathrm{e}}$ and $k$, it is evident that these parameters were dependent on temperature and their values increased with temperature, indicating that the lithium adsorption process is endothermic.

To gain insight into the thermodynamic nature of the adsorption process, several thermodynamic parameters for $\mathrm{HMn}_{2} \mathrm{O}_{4}$ were calculated. The Gibbs free energy change, $\Delta G^{\mathrm{o}}$, was a negative quantity. The free energy of the adsorption reaction is given by the following equation:

$$
\Delta G^{0}=-R T \ln K_{\mathrm{c}}
$$

where $K_{\mathrm{c}}$ is the adsorption equilibrium constant, $R$ is the gas constant and $T$ is the absolute temperature $(\mathrm{K})$. The adsorption equilibrium constant $\left(K_{\mathrm{c}}\right)$ can be calculated from:

$$
F_{\mathrm{e}}=\frac{C_{0}-C_{\mathrm{e}}}{C_{0}}
$$

where $F_{\mathrm{e}}$ is the fraction of lithium ions adsorbed at equilibrium time, and is obtained by the expression

$$
K_{\mathrm{c}}=\frac{F_{\mathrm{e}}}{1-F_{\mathrm{e}}}
$$

where $C_{0}$ and $C_{\mathrm{e}}$ are the initial and equilibrium concentrations of lithium ions in solution $(\mathrm{mg} / \mathrm{L})$.

The values of $K_{\mathrm{c}}$ for the adsorption of lithium ions on the adsorbent were calculated at different temperatures and at equilibrium time using Equations (5) and (6). The variation of $K_{\mathrm{c}}$ with temperature, as summarized in Table 2, showed that $K_{\mathrm{c}}$ values increased with increasing adsorption temperature, thus implying a strengthening of adsorbateadsorbent interactions at higher temperature. Also, the negative values of $\Delta G^{\mathrm{o}}$ obtained confirm the feasibility and the spontaneous nature of the adsorption process.

The Gibbs free energy can be represented as follows:

$$
\Delta G^{0}=\Delta H^{0}-T \Delta S^{0}
$$

The values of enthalpy change $\left(\Delta H^{\circ}\right)$ and entropy change $\left(\triangle S^{\circ}\right)$ calculated from the intercept and slope of the plot of $\Delta G^{\mathrm{o}}$ versus $T$, Fig. 4 , are also given in Table 2. The change in $\Delta H^{\mathrm{o}}$ was found to be positive, confirming that the adsorption process is endothermic, which means that $\mathrm{Li}$ adsorption mainly depends on an endothermic ion exchange reaction. The positive values of entropy $\left(\Delta S^{\circ}\right)$

Table 1 Kinetic parameters for the adsorption of lithium from modified seawater on $\mathrm{HMn}_{2} \mathrm{O}_{4}-1$ and $\mathrm{HMn}_{2} \mathrm{O}_{4}-2$.

\begin{tabular}{|c|c|c|c|c|c|c|}
\hline \multirow{2}{*}{ Reaction temperature $\left({ }^{\circ} \mathrm{C}\right)$} & \multicolumn{3}{|c|}{$\mathrm{HMn}_{2} \mathrm{O}_{4}-1$} & \multicolumn{3}{c}{$\mathrm{HMn}_{2} \mathrm{O}_{4}-2$} \\
\cline { 2 - 8 } & $q_{\mathrm{e}}(\mathrm{mmol} / \mathrm{g})$ & $k(\mathrm{~g} / \mathrm{mmol} / \mathrm{h})$ & $R^{2}$ & $q_{\mathrm{e}}(\mathrm{mmol} / \mathrm{g})$ & $k(\mathrm{~g} / \mathrm{mmol} / \mathrm{h})$ & 0.910 \\
\hline 5 & 1.223 & 0.375 & 0.9928 & 1.041 & 0.9935 \\
\hline 25 & 1.569 & 0.898 & 0.9997 & 1.287 & 0.605 & 0.9966 \\
\hline 60 & 1.533 & 38.014 & 1 & 1.523 & 1.791 & 0.9997 \\
\hline
\end{tabular}


Table 2 Thermodynamic parameters for the adsorption of lithium from modified seawater on $\mathrm{HMn}_{2} \mathrm{O}_{4}-1$.

\begin{tabular}{|c|c|c|c|c|}
\hline Reaction temperature $(\mathrm{K})$ & $K_{\mathrm{c}}$ & $\Delta G^{0}(\mathrm{~kJ} / \mathrm{mol})$ & $\Delta H^{0}(\mathrm{~kJ} / \mathrm{mol})$ & $\Delta S^{0}(\mathrm{~J} /(\mathrm{mol} \cdot \mathrm{K}))$ \\
\hline 278 & 13.7 & -6.06 & & \\
\hline 298 & 89.9 & -11.15 & 59.5 & 236.5 \\
\hline 333 & 999.0 & -19.12 & & \\
\hline
\end{tabular}

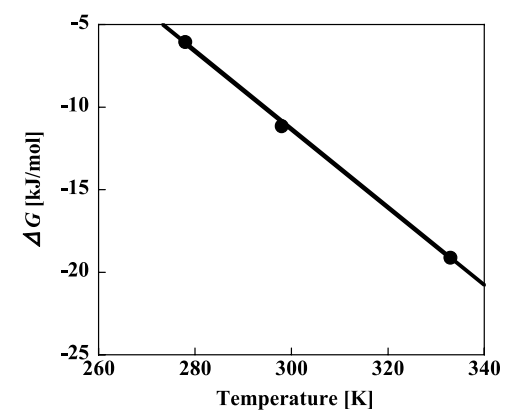

Fig. 4 Relationship between Gibbs free energy change and temperature of adsorption of lithium ions onto the $\mathrm{HMn}_{2} \mathrm{O}_{4}-1$ adsorbent.

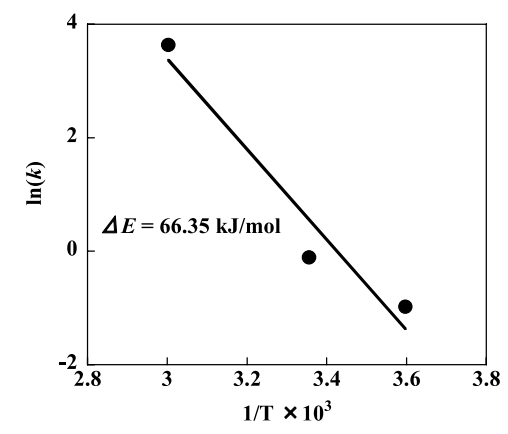

Fig. 5 Arrhenius plot for lithium adsorption onto the $\mathrm{HMn}_{2} \mathrm{O}_{4}-1$ adsorbent.

show increased randomness at the solid/solution interface with some structural changes in the adsorbate and adsorbent.

The activation energy for lithium adsorption in modified seawater was calculated by the Arrhenius equation

$$
k=A \bullet \exp \left(-\frac{\Delta E}{R T}\right)
$$

where $\Delta E$ is the activation energy $(\mathrm{kJ} / \mathrm{mol}), A$ is the frequency factor. From the plot of $\ln (k)$ vs. $1 / \mathrm{T}$ (Fig. 5), the activation energy for the adsorption of lithium in modified seawater was found to be $66.35 \mathrm{~kJ} / \mathrm{mol}$. It is considered that the desorption of $\mathrm{Li}^{+}$in the adsorbent by $\mathrm{H}^{+}$is $6.85 \mathrm{~kJ} / \mathrm{mol}$, which means that the lithium recovery process from the adsorbent needs lower energy than the adsorption process.

\section{Conclusion}

We prepared a lithium adsorbent $\left(\mathrm{HMn}_{2} \mathrm{O}_{4}\right)$ by elution of spinel-type lithium di-manganese-tetra-oxide $\left(\mathrm{LiMn}_{2} \mathrm{O}_{4}\right)$, and the kinetics of the adsorbent for lithium ions in seawater were examined using a pseudo-secondorder kinetic model. The intermediates, $\mathrm{LiMn}_{2} \mathrm{O}_{4}$, can be synthesized from $\mathrm{LiOH} \cdot \mathrm{H}_{2} \mathrm{O}$ and $\mathrm{Mn}_{3} \mathrm{O}_{4}$, and the adsorbent, $\mathrm{HMn}_{2} \mathrm{O}_{4}$, which can recover lithium ion from seawater, can be prepared from the intermediates via acid treatment. The adsorption kinetics of lithium ions from modified seawater follows a pseudo second-order model and the temperature of the solution influences the lithium adsorption. The amount and rate of lithium adsorption both increase with increasing temperature of the solution. Lithium adsorption from seawater using the adsorbent was an endothermic and spontaneous process.

\section{Acknowledgements}

This work was performed with the support and under the auspices of the NIFS Collaboration Research Program (NIFS NIFS10KERA002).

[1] J.N. Hartley et al., Energy 3, 337 (1978).

[2] United States Geological Survey, Mineral Commodity Summaries, 2011, p.94.

[3] T. Wajima et al., Proc. Renew. Energy 2006, p.1489.

[4] E. Kunugita et al., Kagaku Kogaku Ronbunshu 16, 1045 (1990).

[5] R. Chitrakar et al., Ind. Eng. Chem. Res. 40, 2054 (2001).

[6] M. Abe et al., Water Treat. 5, 425 (1990).

[7] W. Tang et al., J. Solid State Chem. 142, 142 (1991).

[8] M. Abe et al., Hydrometallurgy 12, 83 (1984).

[9] P.C. Ho et al., J. Chromatogr. 147, 263 (1978).

[10] K. Ooi et al., J. Min. Met. Inst. Jpn. 99, 931 (1983).

[11] G. Alberti, J. Inorg. Nucl. Chem. 32, 1719 (1970).

[12] K. Ooi et al., Chem. Lett. 17, 989 (1988).

[13] K. Ooi et al., Langmuir 5, 150 (1989).

[14] K. Ooi et al., Langmuir 7, 1167 (1991).

[15] K. Yoshizuka et al., Ars Separatoria Acta 1, 79 (2002).

[16] A. Kitajou et al., Ars Separatoria Acta 2, 97 (2003).

[17] K. Yoshizuka et al., Ars Separatoria Acta 4, 78 (2006).

[18] H. Ohtaki, Ion no Suiwa (Kyoritu-syuppan, Tokyo, 1990) (in Japanese).

[19] Y.S. Ho, Process Saf. Environ. Prot. 76B, 183 (1998).

[20] Y.S. Ho, Process Biochem. 34, 451 (1999). 